\title{
Attitudes about genetic testing and genetic testing intentions in African American women at increased risk for hereditary breast cancer
}

Lisa Kessler, MS, CGCl $C^{1}$ Aliya Collier, BA ${ }^{1}$, Kiyona Brewster, $M A^{1}$, ChaChira Smith ${ }^{2}$, Benita Weathers, MPH ${ }^{1}$, E. Paul Wileyto, $\mathrm{PhD}^{1}$, and Chanita Hughes Halbert, $\mathrm{PhD}^{1,2}$

\begin{abstract}
Purpose: To evaluate attitudes about the benefits, limitations, and risks of genetic testing for BRCA1 and BRCA2 (BRCA1/2) mutations and explore testing intentions in African American women at increased risk for hereditary breast cancer. Methods: Attitudes and intentions were evaluated by telephone in African American women $(n=74)$ at moderate and high risk for having a BRCA1/2 mutation. Results: Attitudes about the benefits of genetic testing were endorsed at a higher rate relative to limitations and risks; however, only $30 \%$ of respondents indicated that they would definitely have testing. In regression analysis, women most likely to be considering testing were those with fatalistic beliefs about cancer and those who believed they had a BRCA1/2 mutation. Women who had two or more affected relatives were also most likely to be considering testing. Women who had a personal history of cancer and those who believed they were at high risk for developing breast cancer were most likely to report greater limitations and risks. Pros scores were higher among women older than age 50 and those who were unemployed. Conclusion: Although African American women at moderate and high risk for BRCA1/2 mutations report favorable attitudes about genetic testing, interest in testing may be limited. Women affected with cancer and those who believe they are at a higher risk for developing breast cancer may be most concerned about the negative consequences of testing. Increased attention may need to be given to beliefs about genetic testing and testing motivations during genetic counseling with African American women. Genet Med 2005:7(4):230-238.
\end{abstract}

Key Words: African American, attitudes, genetic testing

Genetic counseling and testing for BRCA1 and BRCA2 (BRCA1/2) mutations are now available to individuals at increased risk for having a gene mutation. If found to carry a risk-conferring mutation, women have a $60 \%$ to $80 \%$ lifetime risk of developing breast cancer and a $10 \%$ to $45 \%$ lifetime risk of developing ovarian cancer. ${ }^{1-4}$ In addition to providing cancer risk information to individuals who are tested, $B R C A 1 / 2$ genetic test results also have implications for family members. $B R C A 1 / 2$ mutations are transmitted through autosomal-dominant inheritance and first-degree relatives (FDRs) of mutation carriers have a $50 \%$ chance of having the BRCA1/2 mutation identified in a family member. Recent epidemiological studies have shown that the prevalence of $B R C A 1 / 2$ mutations ranges between $16 \%$ and $21 \%$ in African American women with a personal and family history of breast and/or ovarian cancer ${ }^{5-7}$; efforts are being made to increase access to genetic counseling

From the ${ }^{1}$ Department of Psychiatry and ${ }^{2}$ Abramson Cancer Center, University of Pennsylvania, Philadelphia, Pennsylvania.

Chanita Hughes Halbert, PhD, University of Pennsylvania, 3535 Market Street, Suite 4100, Philadelphia, PA 19104.

Received: August 18, 2004.

Accepted: January 10, 2005.

DOI: 10.1097/01.GIM.0000159901.98315.FE and testing among African American women. However, limited empirical data are available on attitudes about genetic testing or interest in genetic testing for BRCA1/2 mutations in African American women at increased risk for hereditary breast cancer.

Previous studies have examined attitudes about genetic testing and testing intentions in African American women at low risk for having a $B R C A 1 / 2$ mutation $^{8-10}$ (e.g., unaffected African American women without a personal or family history of breast and/or ovarian cancer) and in unaffected women with one first-degree relative diagnosed with breast and/or ovarian cancer. ${ }^{11-13}$ Attitudes about genetic testing and intentions were evaluated in a recent study that included African Americans at high risk for having a BRCA1 mutation; more than $80 \%$ of participants in this study indicated that they would definitely have genetic testing. ${ }^{14}$ However, the results from this study have limited generalizability because participants were from a single family identified from a hereditary breast cancer registry. Empirical data on attitudes about genetic testing and testing intentions are needed among more generalizable samples of African American women at increased risk for having a BRCA1/2 mutation.

The purpose of the present study was to evaluate attitudes about the benefits, limitations, and risks of genetic testing for 
$B R C A 1 / 2$ mutations and to explore genetic testing intentions among African American women at increased risk for hereditary breast cancer. Although previous studies have compared African American and Caucasian women in terms of attitudes and intentions, ${ }^{9,11}$ we were interested in exploring these variables specifically in African American women. Ethnic group comparisons in attitudes about genetic testing and genetic testing intentions have been critical to characterizing differences in beliefs about genetic testing and interest in utilizing this service between African American and Caucasian women; however, a better understanding of within-group variation in attitudes and interest among African American women is needed to develop more effective genetic counseling protocols for this population. Therefore, a second objective of this study was to identify factors having independent associations with attitudes about genetic testing and testing intentions specifically in African American women at increased risk for hereditary disease. Because previous research has shown that fatalism is negatively associated with genetic testing intentions among African American men, ${ }^{15}$ we were particularly interested in evaluating the association between fatalistic beliefs about cancer and intentions to have genetic testing for inherited breast cancer risk among African American women.

\section{MATERIALS AND METHODS}

\section{Study population}

This study was conducted at the University of Pennsylvania following approval from the Institutional Review Board. Participants were African American women at increased risk for having a $B R C A 1 / 2$ mutation $(n=74)$. To be eligible, women had to have a $5 \%$ to $10 \%$ prior probability of having a $B R C A 1 / 2$ mutation based on their personal and family history of breast and/or ovarian cancer. A $5 \%$ to $10 \%$ prior probability of having a BRCA1/2 mutation is considered to be the lower bound for clinical genetic testing. ${ }^{16}$ To determine eligibility, probability of having a BRCA1/2 mutation was estimated based on the individual's personal and family history of breast and/or ovarian cancer using risk estimation models from previous research. ${ }^{16-19}$ We also used mutation prevalence tables to estimate empiric risk of having a $B R C A 1 / 2$ mutation. ${ }^{6}$ All women completed a baseline telephone interview as part of their participation in a randomized trial comparing alternate models of genetic counseling. Sixty-one percent of eligible women contacted completed the baseline telephone interview.

\section{Procedures}

Subjects were recruited to participate in the study through referrals from physicians and clinic staff at the University of Pennsylvania Health System and community hospitals and health clinics located in Philadelphia, PA, or through self-referrals. Subjects recruited through physicians and staff were told about the study during a clinic visit. Women were also recruited into the study by clinic staff at health fairs and African American breast cancer support groups. Specifically, written information about the study was given to women at health fairs after a description of the project and presentations about the study were given at breast cancer support groups. Women could also self-refer to the study by responding to newspaper advertisements. Women who were interested in participating in the study contacted research staff directly or completed a referral form. After referral, eligible women were mailed an introductory letter. The introductory letter described the purpose of the study and the procedures involved in participating. A reply card was included with the introductory letter for women to return indicating their interest in participating in the study. Women who did not decline participation were contacted for the baseline telephone interview about two weeks after the introductory letter was mailed. It should be noted that some women $(n=11)$ had provided a blood sample as part of a separate study to understand genetic risk factors for breast cancer in African American women before their participation in this study. However, clinical genetic testing for BRCA1/2 mutations was not performed on these blood samples and none of these individuals received genetic test results before the present study. Provision of a blood sample was controlled for in the statistical analysis.

The baseline telephone interview was a structured survey that took approximately 40 mintues to complete. This interview was administered by a research assistant at Penn and assessed sociodemographics, personal and family history of breast and ovarian cancer, fatalistic beliefs about cancer, perceived risk and control variables, attitudes about genetic testing, and genetic testing intentions. After the interview, consenting subjects were randomized to one of two genetic counseling protocols. The present article focuses on data collected during the baseline telephone interview before genetic counseling.

\section{Predictor variables}

\section{Sociodemographic characteristics}

Age, income level, marital status, education level, and employment status were obtained during the baseline telephone interview.

\section{Clinical factors}

The number of relatives diagnosed with breast and ovarian cancer was obtained during the baseline telephone interview. Prior probability of having a $B R C A 1 / 2$ mutation (moderate or high) was estimated based on women's personal and family history of cancer using risk estimation models and empiric risk data from previous research. ${ }^{6,16-19}$

\section{Beliefs about cancer}

Fatalistic beliefs about cancer were measured using items from the Powe Fatalism Inventory (PFI)..$^{20}$ The PFI is a 15-item instrument that measures fatalistic beliefs about cancer; however, because previous research has shown that all items load on one factor and the instrument has high internal consistency $($ Cronbach's alpha $=0.84),{ }^{20}$ we used two items from the PFI in this study. Because genetic testing provides information 
about future disease risks and may generate fear about cancer, we selected items that represented fatalistic beliefs about disease risks and fatalistic beliefs about getting checked for cancer. Specifically, respondents were asked if they believed that getting checked for cancer makes people scared that they may really have cancer (true or false) and if someone is meant to have cancer, they will have cancer (true or false).

\section{Perceptions of risk and control}

We used two Likert-style items to evaluate perceived risk and control over developing breast cancer. Specifically, respondents were asked what their chances of getting breast cancer were compared to other women their age $(1=$ much lower, $2=$ a little lower, $3=$ about the same, $4=$ a little higher, $5=$ much higher) and how much control they had over whether they develop breast cancer $(1=$ none at all, $2=$ a little, $3=a$ moderate amount, $4=$ a lot). Respondents who had a personal history of breast and/or ovarian cancer were asked to indicate their perceived risk of developing breast cancer again and their perceived control over developing this disease again. These items were adapted from items used and validated in prior reports among women at increased risk for developing breast cancer ${ }^{21,22}$ and women with a personal history of breast cancer. ${ }^{23,24}$ These items have also been used in previous research with African American women ${ }^{25}$ and in research on education and counseling about hereditary breast cancer. ${ }^{26}$ Respondents were also asked to indicate how likely it was that they had a $B R C A 1 / 2$ mutation using a Likert style item $(1=$ not at all likely, 2 = somewhat likely, 3 = very likely, $4=$ definitely). This item has been validated in previous research on interest in genetic testing among Caucasian women ${ }^{27}$ and has been used in prior studies on education and counseling about hereditary breast cancer and genetic testing among African American and Caucasian women. ${ }^{28}$

\section{Outcome variables}

\section{Attitudes about genetic testing}

Attitudes about genetic testing were evaluated using a 14item Likert-style questionnaire that assessed the potential benefits, limitations, and risks of genetic testing for inherited breast cancer risk. The questionnaire consisted of two factors: perceptions of the benefits of genetic testing (pros) and perceptions of the limitations and risks of genetic testing (cons). Specifically, pros items measured the importance of obtaining information about cancer risk and information that would facilitate decisions about health care (e.g., reduce uncertainty, to know if cancer screening tests are needed more often), whereas cons items measured the importance the emotional, familial, and ethical impact of genetic testing (e.g., concern about the impact of testing on family members, unable to handle the emotional impact of testing). Respondents were asked to rate the importance of each reason in their decision to be tested for inherited breast cancer susceptibility. This instrument has been validated in previous research on attitudes about genetic testing in African American women who have a family history of breast and/or ovarian cancer. ${ }^{11}$ Both the pros and cons scales had good internal consistency in this sample (Cronbach's alpha $=0.86$ for pros and 0.70 for cons). Scores for both pros and cons ranged between 7 and 21 .

\section{Genetic testing intentions}

A Likert-style item was used to evaluate genetic testing intentions. Specifically, respondents were asked if they were (1) not considering or have not thought about having genetic testing for breast-ovarian risk, (2) considering genetic testing, (3) probably will have genetic testing, or (4) definitely will have genetic testing. This item had acceptable face validity and has been used to measure the outcome of providing education about hereditary breast cancer and genetic testing to African American women in prior reports. ${ }^{28,29}$

\section{Data analysis}

First, frequencies were generated to characterize respondents in terms of sociodemographic characteristics and clinical factors. Frequencies were also generated to characterize responses to items measuring attitudes about genetic testing. In addition, descriptive statistics were generated to describe mean levels of pros and cons and to characterize interest in genetic testing. Next, we conducted bivariate analyses to evaluate the association between predictor variables and pros, cons, and testing intentions. Because pros and cons scores were not normally distributed, we used nonparametric analysis of variance with the Kruskal-Wallis chi square statistic to evaluate the association between pros and cons and sociodemographics, clinical factors, fatalistic beliefs about cancer, and perceived risk and control variables. Next, we used chi square tests of association to evaluate the relationship between predictor variables and genetic testing intentions. We also used nonparametric analysis of variance to evaluate the association between genetic testing intentions and pros and cons. Testing intentions were recoded into a dichotomous variable (considering versus not considering) for these analyses. To identify factors having independent associations with genetic testing intentions, we conducted backward stepwise logistic regression analysis. We used this same strategy to identify factors having independent associations with attitudes about genetic testing after recoding these variables into dichotomous variables. We used the median split to recode attitudes about genetic testing into dichotomous variables. The median value for cons was 9; respondents who scored at or below 9 were categorized as perceiving few limitations and risks and those who scored above 9 were categorized as perceiving greater limitations and risks. This same procedure was used to dichotomize continuous scores for attitudes about the benefits of genetic testing (median value $=20$ ). All variables with significant bivariate associations with attitudes and intentions $(P<0.10)$ were included in the initial model for each variable after controlling for prior provision of a blood sample. 


\section{RESULTS}

\section{Sample characteristics}

As shown in Table 1, most respondents were ages 50 and younger $(54 \%)$, were not married $(61 \%)$, had some college education $(72 \%)$, were employed $(68 \%)$, and had an annual household income of $\$ 35,000$ or more (53\%). In terms of clinical factors, most respondents had a personal history of breast and/or ovarian cancer $(76 \%)$, had two or more relatives affected with breast and/or ovarian cancer (57\%), and were at high risk for having a BRCA1/2 mutation (50\%).

\section{Descriptive information on attitudes about genetic testing}

Overall, the benefits of genetic testing were endorsed at a higher rate than the limitations and risks of genetic testing. The mean pros score was 18.69 ( $\mathrm{SD}=3.3)$, whereas the mean cons score was $10.05(\mathrm{SD}=3.0)$. As shown in Figure 1 , the most important benefit of genetic testing was to know if additional steps are needed to prevent cancer. The least important benefit of genetic testing was to make childbearing decisions; however, more than half $(65 \%)$ of respondents indicated that this would be a very important benefit of genetic testing. The proportion of respondents rating the limitations and risks of genetic testing is provided in Figure 2. The most important limitation or risk of genetic testing was concern about the impact of testing on family members (25\% rated very important) while the least important limitation or risk was the belief that cancer could not be prevented ( $5 \%$ rated very important).

Table 1

Sample characteristics $(\mathrm{n}=74)$

\begin{tabular}{|c|c|c|}
\hline Variable & Level & $\mathrm{n}(\%)$ \\
\hline \multirow[t]{2}{*}{ Age } & $\leq 50$ & $40(54 \%)$ \\
\hline & $>50$ & $34(46 \%)$ \\
\hline \multirow[t]{2}{*}{ Marital status } & Not married & $45(61 \%)$ \\
\hline & Married & $29(39 \%)$ \\
\hline \multirow[t]{2}{*}{ Education level } & $>$ Some college & $53(72 \%)$ \\
\hline & $\leq$ High school & $21(28 \%)$ \\
\hline \multirow[t]{2}{*}{ Employment status } & Employed & $50(68 \%)$ \\
\hline & Not employed & $24(32 \%)$ \\
\hline \multirow[t]{2}{*}{ Income level $^{a}$} & $>\$ 35,000$ & $39(53 \%)$ \\
\hline & $\leq \$ 35,000$ & $34(47 \%)$ \\
\hline \multirow[t]{2}{*}{ Cancer history } & Affected & $56(76 \%)$ \\
\hline & Unaffected & $18(24 \%)$ \\
\hline \multirow[t]{2}{*}{ Family history of cancer } & Two or more relatives & $42(57 \%)$ \\
\hline & Less than two relatives & $32(43 \%)$ \\
\hline \multirow[t]{2}{*}{$B R C A 1 / 2$ risk level } & High & $37(50 \%)$ \\
\hline & Moderate & $37(50 \%)$ \\
\hline
\end{tabular}

${ }^{a}$ One respondent was missing data for income.

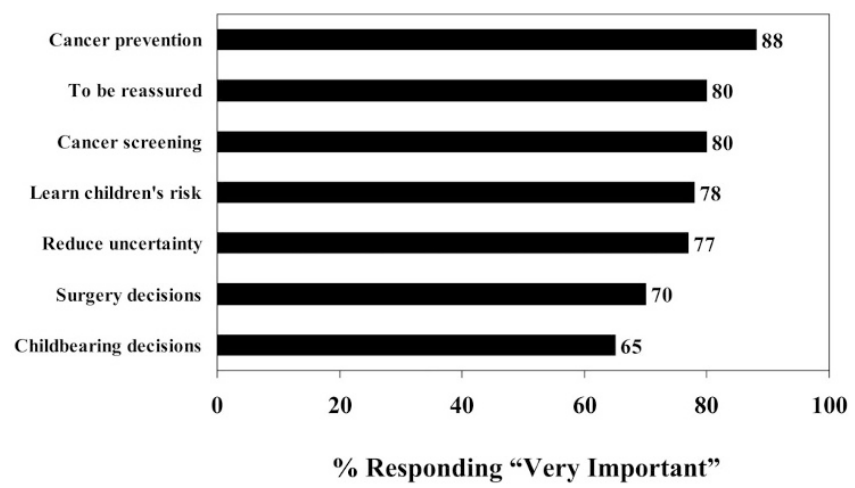

Fig. 1. Attitudes about the benefits of genetic testing.

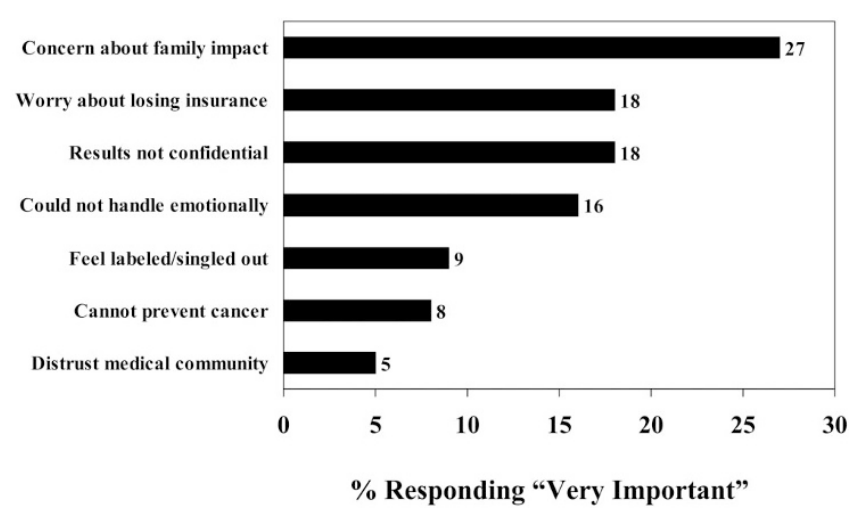

Fig. 2. Attitudes about the limitations and risks of genetic testing.

\section{Bivariate analysis of attitudes about genetic testing}

As shown in Table 2, only age and employment status were associated significantly with pros. Pros scores were significantly higher among women who were older than age 50 and among those who were not employed compared to women who were ages 50 and younger and those who were employed. Fatalistic beliefs about cancer, perceived risk and control over developing breast cancer, and perceived risk of having a BRCA1/2 mutation were not associated significantly with pros. However, these factors were marginally associated with cons. Women who believed that they had a higher or much higher risk for developing breast cancer reported greater cons compared to women who believed that they had the same or lower risk. However, cons were higher among women who believed that they had a moderate or a lot of control over whether they develop breast cancer compared to those who believed they had no or a little control. Beliefs about cancer screening, marital status, education level, $B R C A 1 / 2$ prior probability, and family history of breast and ovarian cancer, and prior provision of a blood sample were not associated significantly with pros or cons.

\section{Descriptive information on genetic testing intentions}

Consistent with the favorable attitudes about the benefits of genetic testing, most respondents reported that they were contemplating having testing for inherited breast cancer risk. However, only $30 \%$ reported that they would definitely have genetic 
Table 2

Association between attitudes about genetic testing and sociodemographic characteristics, clinical factors, and perceived risk and control $(\mathrm{n}=74)$

\begin{tabular}{|c|c|c|c|c|c|}
\hline Variable & Level & Pros Mean (SD) & $\begin{array}{l}\text { Nonparametric } \\
\text { Comparison }^{a}\end{array}$ & Cons Mean (SD) & $\begin{array}{l}\text { Nonparametric } \\
\text { Comparison }^{d}\end{array}$ \\
\hline \multicolumn{6}{|c|}{ Sociodemographics and clinical factors } \\
\hline \multirow[t]{2}{*}{ Prior blood sample } & Yes & $18.82(4.2)$ & 0.51 & $9.36(2.2)$ & 0.27 \\
\hline & No & $18.67(3.1)$ & & $10.18(3.1)$ & \\
\hline \multirow[t]{2}{*}{ Age } & $\leq 50$ & $18.02(3.5)$ & $7.85^{a}$ & $9.90(2.8)$ & 0.09 \\
\hline & $>50$ & $19.47(2.7)$ & & $10.24(3.3)$ & \\
\hline \multirow[t]{2}{*}{ Marital status } & Married & $18.10(3.6)$ & 1.17 & $10.07(2.7)$ & 0.05 \\
\hline & Not married & $19.07(3.0)$ & & $10.04(3.1)$ & \\
\hline \multirow[t]{2}{*}{ Education level } & $>$ Some college & $18.58(3.1)$ & 1.19 & $9.72(2.4)$ & 0.21 \\
\hline & $\leq$ High school & $18.95(3.6)$ & & $10.90(4.2)$ & \\
\hline \multirow[t]{2}{*}{ Employment status } & Employed & $18.38(3.0)$ & $6.23^{a}$ & $9.62(2.6)$ & 1.73 \\
\hline & Not employed & $19.33(3.7)$ & & $10.96(3.6)$ & \\
\hline \multirow[t]{2}{*}{ Income level } & $>\$ 35,000$ & $18.13(3.7)$ & 1.39 & $9.92(2.9)$ & 0.02 \\
\hline & $\leq \$ 35,000$ & $19.26(2.6)$ & & $10.06(3.1)$ & \\
\hline \multirow[t]{2}{*}{ Cancer history } & Affected & $18.71(3.4)$ & 0.32 & $10.45(3.2)$ & $3.91^{b}$ \\
\hline & Unaffected & $18.61(2.9)$ & & $8.83(2.1)$ & \\
\hline \multirow[t]{2}{*}{ Family history of cancer } & 2 or more & $18.64(3.1)$ & 0.90 & $9.71(2.8)$ & 0.86 \\
\hline & Less than 2 & $18.75(3.5)$ & & $10.50(3.3)$ & \\
\hline \multirow[t]{2}{*}{$B R C A 1 / 2$ prior probability } & High & $19.05(3.3)$ & 1.29 & $10.19(3.0)$ & 0.13 \\
\hline & Moderate & $18.32(3.2)$ & & $9.92(3.1)$ & \\
\hline \multicolumn{6}{|l|}{ Beliefs about cancer } \\
\hline \multirow[t]{2}{*}{ Screening creates fear } & True & $19.15(2.9)$ & 1.71 & $10.37(3.1)$ & 1.41 \\
\hline & False & $17.90(3.6)$ & & $9.76(3.0)$ & \\
\hline \multirow[t]{2}{*}{ Cancer cannot be prevented } & True & $18.57(3.6)$ & 0.0008 & $10.23(2.7)$ & 0.75 \\
\hline & False & $18.77(3.0)$ & & $9.93(3.2)$ & \\
\hline \multicolumn{6}{|l|}{ Perceived risk and control } \\
\hline \multirow[t]{2}{*}{ Perceived breast cancer risk } & Higher & $18.39(3.9)$ & 0.007 & $10.76(3.4)$ & $2.63^{c}$ \\
\hline & Lower/same & $18.88(2.6)$ & & $9.45(2.6)$ & \\
\hline \multirow[t]{2}{*}{ Perceived control } & None/a little & $18.92(3.2)$ & 0.77 & $9.49(2.7)$ & $2.96^{c}$ \\
\hline & Moderate/a lot & $18.43(3.4)$ & & $10.69(3.3)$ & \\
\hline \multirow[t]{2}{*}{ Perceived $B R C A 1 / 2$ risk } & Likely & $18.52(3.5)$ & 0.31 & $10.42(3.3)$ & 1.27 \\
\hline & Not likely & $19.00(2.7)$ & & $9.38(2.4)$ & \\
\hline
\end{tabular}

${ }^{a} P<0.01$.

${ }^{b} P<0.05$.

${ }^{c} P<0.10$.

${ }^{d}$ Kruskal-wallis chi square with $1_{\mathrm{df}}$.

testing, $22 \%$ indicated that they would probably have genetic testing, and $16 \%$ were considering having genetic testing. Thirty-two percent of respondents reported that they were not considering or had not thought about having genetic testing.

\section{Bivariate analysis of genetic testing intentions}

The results of the bivariate analysis of genetic testing intentions are provided in Table 3. Of the sociodemographic char- acteristics, only age was associated significantly with genetic testing intentions. Women who were ages 50 and younger were significantly more likely to be considering genetic testing compared to women over age 50. Although cancer history was not associated significantly with genetic testing intentions, women who had two or more relatives affected with breast and/or ovarian cancer and those at high risk for having a BRCA1/2 mutation were significantly more likely to be considering ge- 
Table 3

Association between genetic testing intentions and sociodemographic characteristics, clinical factors, and perceived risk and control $(\mathrm{n}=74)$

\begin{tabular}{|c|c|c|c|}
\hline Variable & Level & $\begin{array}{c}\% \\
\text { Considering }\end{array}$ & $\begin{array}{l}\text { Chi } \\
\text { Square }\end{array}$ \\
\hline \multicolumn{4}{|c|}{ Sociodemographics and clinical factors } \\
\hline \multirow[t]{2}{*}{ Prior blood sample } & Yes & $82 \%$ & 1.20 \\
\hline & No & $65 \%$ & \\
\hline \multirow[t]{2}{*}{ Age } & $\leq 50$ & $78 \%$ & $3.92^{a}$ \\
\hline & $>50$ & $56 \%$ & \\
\hline \multirow[t]{2}{*}{ Marital status } & Married & $72 \%$ & 0.51 \\
\hline & Not married & $64 \%$ & \\
\hline \multirow[t]{2}{*}{ Education level } & $>$ Some college & $68 \%$ & 0.01 \\
\hline & $\leq$ High school & $67 \%$ & \\
\hline \multirow[t]{2}{*}{ Employment status } & Employed & $68 \%$ & 0.01 \\
\hline & Not employed & $67 \%$ & \\
\hline \multirow[t]{2}{*}{ Income level } & $>\$ 35,000$ & $72 \%$ & 0.42 \\
\hline & $\leq \$ 35,000$ & $65 \%$ & \\
\hline \multirow[t]{2}{*}{ Cancer history } & Affected & $66 \%$ & 0.23 \\
\hline & Unaffected & $72 \%$ & \\
\hline \multirow[t]{2}{*}{ Family history of cancer } & 2 or more & $78 \%$ & $5.37^{a}$ \\
\hline & Less than 2 & $53 \%$ & \\
\hline \multirow[t]{2}{*}{$B R C A 1 / 2$ prior probability } & High & $78 \%$ & $3.94^{a}$ \\
\hline & Moderate & $57 \%$ & \\
\hline \multicolumn{4}{|l|}{ Beliefs about cancer } \\
\hline \multirow[t]{2}{*}{ Screening creates fear } & True & $76 \%$ & $4.02^{c}$ \\
\hline & False & $54 \%$ & \\
\hline \multirow[t]{2}{*}{ Cancer cannot be prevented } & True & $77 \%$ & 1.91 \\
\hline & False & $61 \%$ & \\
\hline \multicolumn{4}{|l|}{ Perceived risk and control } \\
\hline \multirow[t]{2}{*}{ Perceived breast cancer risk } & $\begin{array}{l}\text { Higher/much } \\
\text { higher }\end{array}$ & $70 \%$ & 0.04 \\
\hline & Lower/same & $68 \%$ & \\
\hline \multirow[t]{2}{*}{ Perceived control } & None/a little & $62 \%$ & 1.37 \\
\hline & Moderate/a lot & $74 \%$ & \\
\hline \multirow[t]{2}{*}{ Perceived $B R C A 1 / 2$ risk } & Likely & $81 \%$ & $11.67^{b}$ \\
\hline & Not likely & $42 \%$ & \\
\hline
\end{tabular}

${ }^{a} P<0.05$.

${ }^{b} P<0.001$.

netic testing compared to women who had a fewer number of affected relatives and women at moderate risk. Fatalistic beliefs about cancer and perceived risk of having a BRCA1/2 mutation were also associated significantly with genetic testing intentions. Seventy-six percent of women who believed that getting checked for cancer generates fear were considering genetic testing compared to $54 \%$ of women who did not endorse this belief (chi square $=4.02 ; P=0.04$ ). In addition, women who believed that they had a $B R C A 1 / 2$ mutation were significantly more likely to be considering genetic testing compared to women who did not believe that they had a mutation. Pros (Kruskal-Wallis chi square $=2.20 ; P=0.14$ ) and cons (Kruskal-Wallis chi square $=1.90 ; P=0.17$ ) were not associated significantly with genetic testing intentions. Perceived risk and control over developing breast cancer and prior provision of a blood sample were also not associated significantly with genetic testing intentions.

\section{Multivariate model of intentions and attitudes about genetic testing}

The results of the regression analyses are provided in Table 4. Because only two factors were associated significantly with pros in bivariate analyses, we did not generate a multivariate regression model for this variable. In the model for cons, perceived control over developing breast cancer was removed on the first step [chi square change $\left(1_{\mathrm{df}}, n=74\right)=2.03 ; P=0.15$ ]. None of the remaining variables could be removed from the model; thus, the final model for cons included cancer history and perceived risk of developing breast cancer. Women affected with cancer were about four times more likely than unaffected women to report greater cons. Women who believed that they were at higher or much higher risk for developing breast cancer were also significantly more likely to report greater cons compared to women who believed they were at the same or lower risk for developing breast cancer.

In the model of genetic testing intentions, age was removed on step one [chi square change $\left(1_{\mathrm{d} f}, n=74\right)=1.19 ; P=0.28$ ], and $B R C A 1 / 2$ risk level was removed on step two [Chi square change $\left.\left(1_{\mathrm{d} f}, n=74\right),=2.21 ; P=0.15\right]$. None of the remaining variables could be removed from the model; thus, the final model for genetic testing intentions included fatalistic beliefs about cancer, perceived risk of having a BRCA1/2 mutation, and the number of relatives affected with breast and/or ovarian cancer. As shown in Table 4, women who believed that cancer screening generates fear were about five times more likely than women who did not endorse this belief to be considering genetic testing. However, women who believed that they had a $B R C A 1 / 2$ mutation were significantly more likely to be considering genetic testing compared to those who did not believe that they have a mutation. Compared to women with fewer affected relatives, those who had two or more relatives affected with breast and/or ovarian cancer were about four times more likely to be considering genetic testing.

\section{DISCUSSION}

Although ethnic differences in attitudes about genetic testing and genetic testing intentions have been evaluated in a number of previous studies, ${ }^{8,9,11,13,29}$ limited empirical data are available on attitudes and intentions specifically among African American women at increased risk for hereditary breast cancer. This study evaluated attitudes about the benefits, limitations, and risks of genetic testing and explored intentions to have testing for inherited breast cancer susceptibility in African 
Table 4

Regression model of testing intentions and attitudes about the limitations and risks of genetic testing $(\mathrm{n}=74)^{b}$

\begin{tabular}{|c|c|c|c|c|}
\hline Outcome variable & Predictor variable & Level & OR & $95 \% \mathrm{CI}$ \\
\hline \multirow[t]{8}{*}{ Intentions } & \multirow[t]{2}{*}{ Prior blood sample } & Yes & 0.61 & \multirow[t]{2}{*}{$0.09,3.93$} \\
\hline & & No & 1.00 & \\
\hline & \multirow[t]{2}{*}{ Beliefs about cancer screening } & True & 5.07 & \multirow[t]{2}{*}{$1.42,18.12^{\circ}$} \\
\hline & & False & 1.00 & \\
\hline & \multirow[t]{2}{*}{ Number of relatives affected with cancer } & Two or more & 4.31 & \multirow[t]{2}{*}{$1.28,14.54^{e}$} \\
\hline & & Less than two & 1.00 & \\
\hline & \multirow[t]{2}{*}{ Perceived risk of $B R C A 1 / 2$} & Likely & 7.48 & \multirow[t]{2}{*}{$2.10,26.60^{c}$} \\
\hline & & Not likely & 1.00 & \\
\hline \multirow[t]{6}{*}{ Cons $^{a}$} & \multirow[t]{2}{*}{ Prior blood sample } & Yes & 1.25 & \multirow[t]{2}{*}{$0.32,4.91$} \\
\hline & & No & 1.00 & \\
\hline & \multirow[t]{2}{*}{ Cancer history } & Affected & 4.07 & \multirow[t]{2}{*}{$1.10,15.06^{e}$} \\
\hline & & Unaffected & 1.00 & \\
\hline & \multirow[t]{2}{*}{ Perceived risk of developing breast cancer } & Higher/much higher & 2.84 & \multirow[t]{2}{*}{$1.04,7.74^{e}$} \\
\hline & & Lower/same & 1.00 & \\
\hline
\end{tabular}

\footnotetext{
${ }^{a}$ Median $=9.00$.

${ }^{b}$ Variables included in the final model.

${ }^{c} \mathrm{P}<.001$

${ }^{d} \mathrm{P}<.01$

${ }^{e} \mathrm{P}<.05$
}

American women at moderate and high risk for having a $B R C A 1 / 2$ mutation. Consistent with prior reports, ${ }^{9,11}$ respondents in the present study reported positive attitudes about genetic testing. Relative to the limitations and risks of genetic testing, the benefits of genetic testing were endorsed at a higher rate by respondents in the present study. Similar to other studies, ${ }^{11}$ the most important benefit of genetic testing was to learn if additional steps are needed to prevent cancer, whereas the least important benefit was to make childbearing decisions. Whereas concern about the impact of testing on family members was the most important limitation or risk of genetic testing in this study and in prior reports, ${ }^{11,30}$ distrust of the medical community was the least important limitation or risk in the present study. Although it is standard practice to identify family members at risk for having a BRCA1/2 mutation during test results disclosure, this finding suggests that concerns about the impact of testing on family members may need to be addressed during pretest genetic counseling and test results disclosure with African American women.

We found that cancer history and perceived risk of developing cancer were associated significantly with cons. Women affected with breast and/or ovarian cancer and those who believed that they were at higher or much higher risk for developing breast cancer were significantly more likely to report greater cons compared to unaffected women and those who did not believe they were at higher risk for developing breast cancer. However, perceived risk of developing breast cancer was not associated with cons in a prior report. ${ }^{9}$ It is possible that different results were obtained in the present study because participants were at moderate and high risk for having a BRCA1/2 mutation, whereas participants in the study conducted by Donovan and Tucker ${ }^{9}$ were not at increased risk for hereditary disease. Another possible explanation is that perceived risk of developing breast cancer was confounded with ethnicity in prior reports. African American women were significantly less likely than Caucasian women to believe that they were at increased risk for developing breast cancer in the study conducted by Donovan and Tucker. ${ }^{9}$ The present study only included African American women and about half reported that they were at higher or much higher risk for developing breast cancer. These findings underscore the importance of evaluating attitudes about genetic testing within specific ethnic groups to minimize the influence of confounding when making ethnic group comparisons.

Although endorsement of the benefits of genetic testing was high in this study, only $30 \%$ of respondents indicated that they would definitely have genetic testing. Previous research has shown that more than $80 \%$ of African Americans at high risk for having a BRCA1/2 mutation reported that they would have genetic testing ${ }^{14}$; however, only $68 \%$ of respondents in the present study reported that they were considering genetic testing. This difference may be due to variations in sample characteristics between the present study and the research by Kinney et al. ${ }^{14}$ The present study included African American women at moderate and high risk for having a BRCA1/2 mutation who were not selected for membership in a family, whereas the study conducted by Kinney and colleagues included African Americans from a single family in which a 
BRCA1 mutation had been previously identified. Some members of this family had provided a blood sample to isolate $B R C A 1^{14}$; thus, these individuals may have been more interested in obtaining their BRCA1 test result. It is also possible that interest was lower in the present study because the sample included women at moderate risk for having a $B R C A 1 / 2 \mathrm{mu}-$ tation. However, $B R C A 1 / 2$ prior probability did not have a significant effect on testing intentions in regression analysis. The number of relatives affected with breast and/or ovarian cancer and perceived risk of having a $B R C A 1 / 2$ mutation were associated significantly with testing intentions in the regression model. Women with a greater number of affected relatives and those who believed that they had a BRCA1/2 mutation were significantly more likely to be considering genetic testing compared to women with fewer affected relatives and those who did not believe they had a BRCA1/2 mutation. Similar results were obtained in the study conducted by Kinney et al. ${ }^{14}$; thus, perceived risk of having a BRCA1/2 mutation and family history of cancer may be most important to genetic testing intentions among African American women.

Surprisingly, women who reported fatalistic beliefs about cancer were significantly more likely to be considering genetic testing compared to women who had less fatalistic beliefs. Specifically, women who believed that screening for cancer generates fear were about five times more likely than those who did not endorse this belief to be considering genetic testing. This finding differs from previous research in which cancer fatalism was associated with less interest in genetic testing for inherited prostate cancer risk. ${ }^{15}$ However, a recent study has shown that cancer fatalism is higher among African American women who participate in genetic counseling and receive $B R C A 1 / 2$ test results compared to those who decline genetic counseling and testing. ${ }^{31}$ Cancer fatalism is a multidimensional construct that includes elements of powerlessness, fear, pessimism, and predetermination. ${ }^{32}$ It is possible that women who had a more fatalistic outlook are interested in genetic testing for inherited breast cancer risk as a way to overcome fear about cancer. Another possible explanation is that women with fatalistic beliefs are more interested in genetic testing because they think that they are predetermined to have BRCA1/2 mutation; interest in testing may be motivated by a desire to confirm this belief. It is important to note that we only used two items to evaluate fatalism and additional research is needed to evaluate the effects of cancer fatalism on utilization of genetic testing in larger samples of African American women at increased risk for hereditary breast cancer.

In considering the results of the present study, several limitations should be noted. First, only $61 \%$ of eligible women completed the baseline telephone interview and the sample included 74 African American women. Although a recent review on minority recruitment demonstrated that the challenges associated with recruiting African American women to participate in medical research may be more extensive in genetic counseling and testing studies, ${ }^{33}$ our participation rates were similar to those reported in other cancer research designed to understand psychosocial issues among African
American women. ${ }^{34,35}$ An additional limitation is that we had approximately $70 \%$ power to detect small to moderate differences in genetic testing intentions between respondents with different beliefs about cancer, family history of disease, and perceived risk of having a $B R C A 1 / 2$ mutation. Further, because of the small sample size, the power to detect differences in perceptions of the limitations and risks based on personal history of disease and perceived risk of developing breast cancer was also limited. We also used single self-report items to measure beliefs about cancer and perceptions of risk and control. Thus, additional studies are needed to understand attitudes and testing intentions in larger samples of African American women at increased risk for hereditary breast cancer using more extensive measures of beliefs about cancer and risk and control perceptions. Another potential limitation is that some women had donated a blood sample for genetics research before their participation in the present study. However, clinical genetic testing for $B R C A 1 / 2$ mutations was not performed on these samples and these women had not received genetic test results before the present study. Provision of a prior blood sample was not associated with attitudes or intentions, and we controlled for this variable in the regression analyses. Finally, we evaluated intentions to have genetic testing rather than actual genetic test acceptance. Prior reports have shown that testing intentions do not translate into similar rates of test acceptance. ${ }^{36,37}$ However, intentions to have genetic testing have not been explored extensively among African American women at increased risk for hereditary breast cancer; thus, the present study provides novel empirical data on interest in genetic testing among an understudied population. Additional research is needed to determine whether interest in genetic testing corresponds to similar rates of genetic test acceptance in African American women at increased risk for having a BRCA1/2 mutation.

Despite these potential limitations, the present study demonstrates that among African American women at increased risk for hereditary breast cancer, attitudes about the limitations and risks of genetic testing may be driven by personal experiences with breast and/or ovarian cancer and perceived risk of developing breast cancer, whereas genetic testing intentions are influenced by beliefs about cancer, family history of disease, and perceived risk of having a BRCA1/2 mutation. These findings suggest that in addition to providing information about one's personal risk of carrying a risk-conferring $B R C A 1 / 2 \mathrm{mu}-$ tation, greater emphasis may need to be given to the familial implications of genetic risk information in genetic counseling and testing programs targeted to African American women. Increased attention may also need to be given to beliefs about genetic testing and motivations for having genetic testing.

\section{ACKNOWLEDGMENTS}

This research was supported by Department of Defense grant no. DAMD17-00-1-0262. We are very grateful to all of the women who participated in this study and would like to acknowledge Wilma Higginbotham for assistance with manuscript preparation. 


\section{References}

1. Antoniou A, Pharoah PD, Narod S, Risch HA, Eyfjorf JE, Hopper JL et al. Average risks of breast and ovarian cancer associated with BRCA1 or BRCA2 mutations detected in case series unselected for family history: a combined analysis of 22 studies. Am J Hum Genet 2003;72:1117-1130.

2. Struewing JP, Hartge P, Wacholder S, Baker SM, Berlin M, McAdams M et al. The risk of cancer associated with specific mutations of BRCA1 and BRCA2 among Ashkenazi Jews. N Engl J Med 1997;336:1401-1408.

3. Easton DF, Ford D, Bishop DT. Breast and ovarian cancer incidence in BRCA1mutation carriers. Am J Hum Genet 1995;56:265-271.

4. Ford D, Easton DF, Stratton M, Narod S, Goldgar D, Devilee P et al, The Breas Cancer Linkage Consortium. Genetic heterogeneity and penetrance analysis of the BRCA1 and BRCA2 genes in breast cancer families. Am J Hum Genet 1998;62:676689

5. Panguluri RC, Brody LC, Modali R, Utley K, Campbell LA, Day AA et al. BRCA1 mutations in African Americans. Hum Genet 1999;105:28-31.

6. Frank TS, Deffenbaugh AM, Reid JE, Hulick M, Ward BE, Lingenfelter B et al. Clinical characteristics of individuals with germline mutations in BRCA1 and BRCA2: analysis of 10,000 individuals. J Clin Oncol 2002;20:1480-1490.

7. Gao Q, Tomlinson G, Das S, Cummings S, Sveen L, Fackenthal J et al. Prevalence of $B R C A 1$ and BRCA2 mutations among clinic-based African American families with breast cancer. Hum Genet 2000;107:186-191

8. Peters N, Rose A, Armstrong K. The association between race and attitudes about predictive genetic testing. Cancer Epidemiol Biomarkers Prev 2004;13:361-365.

9. Donovan KA, Tucker DC. Knowledge about genetic risk for breast cancer and perceptions of genetic testing in a sociodemographically diverse sample. J Behav Med 2000;23:15-36.

10. Gwyn K, Vernon SW, Conoley PM. Intention to pursue genetic testing for breast cancer among women due for screening mammography. Cancer Epidemiol Biomarkers Prev 2003;12:96-102.

11. Hughes C, Caminero AG, Benkendorf J, Kerner J, Isaacs C, Barter J et al. Ethnic differences in knowledge and attitudes about BRCA1 testing in women at increased risk. Patient Educ Couns 1997;32:51-62.

12. Lipkus IM, Iden D, Terrenoire J, Feaganes JR. Relationships among breast cancer concern, risk perceptions, and interest in genetic testing for breast cancer susceptibility among African American women with and without a family history of breast cancer. Cancer Epidemiol Biomarkers Prev 1999;8:533-539.

13. Durfy SJ, Bowen DJ, McTiernan A, Sporleder J, Burke W. Attitudes and interest in genetic testing for breast and ovarian cancer susceptibility in diverse groups of women in western Washington. Cancer Epidemiol Biomarkers Prev 1999;8:369-375.

14. Kinney AY, Croyle RT, Dudley WN, Bailey CA, Pelias MK, Neuhausen SL. Knowledge, attitudes, and interest in breast-ovarian cancer gene testing: A survey of a large African American kindred with a BRCA1 mutation. Prev Med 2001;33:543-551.

15. Myers RE, Hyslop T, Dozier KJ, Wolf TA, Burgh DY, Diehl JA et al. Intention to be tested for prostate cancer risk among African American men. Cancer Epidemiol Biomarkers Prev 2000;9:1323-1328.

16. Domchek SM, Eisen A, Calzone K, Stopfer J, Blackwood A, Weber BL. Application of breast cancer risk prediction models in clinical practice. J Clin Oncol 2003;21:593601

17. Parmigiani G, Berry D, Aguillar O. Determining carrier probabilities for breast cancer-susceptibility genes BRCA1 and. BRCA2 Am J Genet 1998;62:145-158.
18. Couch FJ, DeShano ML, Blackwood MA, Calzone K, Stopfer J, Campeau L et al. $B R C A 1$ mutations in women attending clinics that evaluate the risk of breast cancer. N Engl J Med 1997;336:1409-1415.

19. Blackwood MA, Yang H, Margolin A. Predicted probability of breast cancer susceptibility gene mutations. Breast Cancer Res Treat 2001;69:223.

20. Powe BD. Cancer fatalism among elderly Caucasians and African Americans. Oncol Nurs Forum 1995;22:1355-1359.

21. Lerman C, Daly M, Sands C, Balshem A, Lustbader E, Heggan T et al. Mammography adherence and psychological distress among women at risk for breast cancer. J Natl Cancer Inst 1993;85:1074-1080.

22. Lerman C, Kash K, Stefanek M. Younger women at increased risk for breast cancer: perceived risk, psychological well-being, and surveillance behavior. J Natl Cance Inst Monogr 1994;16:171-176.

23. Hilton BA. The relationship of uncertainty, control, commitment, and threat of recurrence to coping strategies used by women diagnosed with breast cancer. J Behav Med 1989;12:39-54.

24. Taylor SE, Lichtman RR, Wood JV. Attributions, beliefs about control, and adjustment to breast cancer. J Pers Soc Psychol 1984;43:489-502.

25. Hughes C, Lerman C, Lustbader E. Ethnic differences in risk perception among women at increased risk for breast cancer. Breast Cancer Res Treat 1996;40:23-35.

26. Audrain J, Schwartz MD, Lerman C, Hughes C, Peshkin BN, Biesecker B. Psychological distress in women seeking genetic counseling for breast-ovarian cancer risk: the contributions of personality and appraisal. Ann Behav Med 1997;19:370-377.

27. Lerman C, Daly M, Masny A, Balshem A. Attitudes about genetic testing for breastovarian cancer susceptibility. J Clin Oncol 1994;12:843-850.

28. Lerman C, Biesecker B, Benkendorf JL, Kerner J, Gomez-Caminero A, Hughes C et al. Controlled trial of pretest education approaches to enhance informed decision making for BRCA1 gene testing. I Natl Cancer Inst 1997;89:148-157.

29. Lerman C, Hughes C, Benkendorf JL, Biesecker B, Kerner J, Willison J et al. Racia differences in testing motivation and psychological distress following pretest education for BRCA1 gene testing. Cancer Epidemiol Biomarkers Prev 1999;8:361-367.

30. Thompson HS, Valdimarsdottir HB, Duteau-Buck C, Guevarra J, Bovbjerg DH, Richmond-Avellaneda $\mathrm{C}$ et al. Psychosocial predictors of BRCA counseling and testing decisions among urban African American women. Cancer Epidemiol Biomarkers Prev 2002;11:579-585.

31. Hughes C, Fasaye GA, LaSalle VH, Finch C. Sociocultural influences on participation in genetic risk assessment and testing among African American women. Patient Educ Couns 2003;51:107-114.

32. Powe BD, Finnie R. Cancer fatalism: the state of the science. Cancer Nurs 2003;26: 454-465.

33. Hughes C, Peterson SK, Ramirez A, Gallion KJ, McDonald PG, Skinner CS et al Minority recruitment in hereditary breast cancer research. Cancer Epidemiol Biomarkers Prev 2004:13:1146-1155.

34. Taylor KL, Siegel JE, Klimi KM, Lamdan RM, Shelby R, Hrywna M. Psychologica adjustment among African American breast cancer patients: one-year follow-up results of a randomized psychoeducational group intervention. Health Psychol 2003 $22: 316-323$

35. Giwa KA, Ganz PA, Peterson L. Quality of life of African American and white long term breast carcinoma survivors. Cancer 1999;85:418-426.

36. Lerman C, Seay J, Bakshem A, Audrain J. Interest in genetic testing among first degree relatives of breast cancer patients. Am J Med Genet 1995;57:385-392.

37. Lerman C, Narod S, Schulman K, Hughes C, Caminero AG, Boney G, Gold K et al BRCA1 testing in families with hereditary breast-ovarian cancer: A prospective study of patient decision making and outcomes. JAMA 1996;275:1885-1892. 